\title{
МОДЕЛИРОВАНИЕ ДИНАМИКИ ЛЕСНЫХ ПОЖАРОВ ПО МНОГОЛЕТНИМ СТАТИСТИЧЕСКИМ ДАННЫМ
}

\author{
П.М. Мазуркин
}

Поволжский государственный технологический университет, kaf_po@mail.ru

Показан метод анализа по многолетним статистическим данным множества лесных пожаров от времени регистрации. Шкалу времени регистрации лесных пожаров в прошлом измеряют в сутках, а за нулевое значение времени регистрации принимают момент первого зарегистрированного в книге учета лесного пожара. Из книги учета принимают первичные показатели о лесных пожарах, выполняют корректировку статистических данных относительно принятой шкалы времени регистрации лесных пожаров, дополнительно учитывают производные от первичных показатели. Приведены статистические модели каждого первичного и производного от него показателя в зависимости от времени регистрации лесных пожаров. Изложен кратко метод идентификации волновых функций в виде асимметричных вейвлет-сигналов.

Ключевые слова: лесные пожары, показатели, измерение, динамика, закономерности, вейвлет-сигналы

\section{MODELLING OF DYNAMICS OF FOREST FIRES ACCORDING TO LONG-TERM STATISTICAL DATA}

P.M. Mazurkin

Volga State Technological University, kaf_po@mail.ru

The analysis method according to long-term statistical data of a set of forest fires from registration time is shown. Time scale of registration of forest fires in the past measure in days, and for zero value of time of registration take the moment of the first account of forest fire registered in the book. From the book of the account accept primary indicators about forest fires, carry out updating of statistical data of rather accepted time scale of registration of forest fires, in addition consider derivatives from primary indicators. Statistical models of indicator everyone primary and derivative of it depending on time of registration of forest fires are given. The method of identification of wave functions in the form of asymmetric wavelet signals is stated briefly.

Keywords: forest fires, indicators, measurement, dynamics, regularities, wavelet signals.

Введение. Предлагаемый метод физико-математического анализа [1-7] относится к предупреждающим системам тревожной сигнализации, использующим статистические данные о многолетней динамике лесных пожаров в национальных парках, заповедниках и других видах особо охраняемых территорий.

Недостатком существующих методов является отсутствие регистрации текущего календарного времени возникновения, обнаружения, начала тушения и окончания тушения пожара. И это не дает систематизировать накапливающийся массив количественной информации по множеству учитываемых факторов. 
Цель метода - повышение функциональных возможностей системы типа «Лесной Дозор», а также точности инерционного прогнозирования лесных пожаров в будущем, с использованием многолетних данных о лесных пожарах на территории мониторинга по выявленным статистическим моделированием закономерностям, а также ориентировочный прогнозный расчет по ним значений параметров будущих лесных пожаров.

Сущность метода. Совокупность лесных пожаров принимается за динамическую популяцию, поведение которой изменяется во времени регистрации лесных пожаров на одной и той же территории. Это время измеряется сутками, равными циклу вращения Земли вокруг своей оси, и принимается за влияющую переменную для всех первичных (измеренных) и производных из первичных (расчетных) показателей лесных пожаров.

Время обнаружения и окончания тушения, а также разность между ними как период лесного пожара, из обычной системы исчисления времени (часы, минуты и секунды) преобразуются в десятичной системе счисления (в часах и десятичных долях часа).

Реализация способа. Книга учета лесных пожаров постоянно пополняется данными о новых лесных пожарах, поэтому предлагаемый метод позволяет поводить итерационное моделирование, причем даже в реальном режиме времени, что и требуется для повышения функциональных возможностей системы «Лесной дозор».

Шкалу времени регистрации лесных пожаров измеряют в сутках по физическому циклу обращения Земли вокруг своей оси, а за нулевое значение времени регистрации принимают момент первого зарегистрированного на данной территории лесного пожара в книге учета лесных пожаров. Затем из книги учета лесных пожаров принимают первичные показатели о лесных пожарах и выполняют корректировку статистических данных относительно принятой шкалы времени регистрации. Дополнительно, вне книги учета лесных пожаров, учитывают производные показатели, а затем выполняют статистическое моделирование каждого первичного и производного от него показателя в зависимости от времени регистрации лесных пожаров идентификацией математических волновых функций [1,2] в виде асимметричных вейвлет-сигналов [3-12].

За постоянно заданную территорию принимают площадь особо охраняемой территории, а за многолетние статистические данные принимают совокупность прошлых зарегистрированных лесных пожаров не менее чем за пять лет.

Для физико-математического анализа многолетних данных о лесных пожарах, например, по площади каждого лесного пожара, применяется общая формула $[1,2]$ :

$$
y_{i}=A_{i} \cos \left(\pi x / p_{i}-a_{8 i}\right), A_{i}=a_{1 i} x^{a_{2 i}} \exp \left(-a_{3 i} x^{a_{4 i}}\right), p_{i}=a_{5 i}+a_{6 i} x^{a_{7 i}}
$$


где $y$ - показатель (зависимый фактор), например, площадь лесного пожара, га, $i$ - номер составляющей модели, причем $i=1,2,3, \ldots, m, m-$ количество членов в модели, $x-$ объясняющая переменная (влияющий фактор), время регистрации в сутках, $a_{1} \ldots a_{10}-$ параметры, принимающие числовые значения в ходе структурно-параметрической идентификации $[1,2]$ модели по мере увеличения коэффициента корреляции.

Для особо охраняемых территорий корректировка массива исходных данных при исключении резко отклоняющиеся точек показывает оперативность деятельности службы пожаротушения по максимуму периода тушения за многолетний период. Причем такие выбросы отдельно для каждого случая лесного пожара моделируют импульсной функцией гауссова закона нормального распределения [3-5], а отношение количества оставшихся малых выбросов к общему числу лесных пожаров за много лет показывает качество функционирования службы пожаротушения.

Объект исследования. Государственный природный Национальный парк «Марий Чодра» организован 1 декабря 1985 года. Марий Чодра, в переводе, означает «марийский лес». И назван он так не случайно - вся территория парка покрыта прекрасными сосновыми борами и хвойно-широколиственными лесами. Парк находится на юговостоке республики, в трех административных районах - Моркинском, Звениговском, Волжском - в 20-40 километрах от г. Волжска и 50-70 километрах от г. Йошкар-Олы.

Регистрация пожаров. Книга учета лесных пожаров ФГБУ «Национальный парк «Марий Чодра» представляет собой журнал, в котором составитель акта о пожаре лесничества, где произошло возгорание, записывает известные ему данные о возгорании.

Книга учета лесных пожаров ведется в НП «Марий Чодра» с 1982 г. (табл. 1).

Таблица 1. Данные по лесным пожарам за 1982-2011 гг.

\begin{tabular}{|c|c|c|c|c|c|c|c|}
\hline \multirow[b]{2}{*}{ Дата } & \multicolumn{3}{|c|}{ Моменты времени, ч : мин } & \multirow[b]{2}{*}{ Лесничество } & \multirow[b]{2}{*}{$\begin{array}{c}\text { Квар- } \\
\text { тал }\end{array}$} & \multirow[b]{2}{*}{$\begin{array}{c}\text { Преобла- } \\
\text { дающая } \\
\text { порода }\end{array}$} & \multirow{2}{*}{$\begin{array}{c}\text { Пло- } \\
\text { щадь } \\
\text { лесная } \\
\text { (га) }\end{array}$} \\
\hline & $\begin{array}{c}\text { Обнару- } \\
\text { жение } \\
\text { пожара }\end{array}$ & $\begin{array}{c}\text { Начало } \\
\text { тушения }\end{array}$ & $\begin{array}{c}\text { Окон- } \\
\text { чание } \\
\text { тушения }\end{array}$ & & & & \\
\hline 01.08 .1982 & 19:35 & $20: 05$ & $5: 20$ & Яльчинское & 84 & сосна & 0.6 \\
\hline 16.08 .1982 & $16: 50$ & - & $8: 30$ & Лушмарское & 61 & дуб & 0 \\
\hline 27.08 .1982 & $14: 55$ & 18:00 & 19:00 & Кленовогорское & 54 & сосна & 0.03 \\
\hline 30.08 .1982 & $15: 50$ & $16: 00$ & 14:00 & Лушмарское & 24 & береза & 0.02 \\
\hline 30.08 .1982 & 18:00 & $18: 40$ & 22:00 & Кленовогорское & 26 & сосна & 0.02 \\
\hline 02.09 .1982 & $16: 50$ & $17: 00$ & $20: 00$ & Яльчинское & 80 & сосна & 0.02 \\
\hline 15.05 .1983 & $16: 00$ & $16: 30$ & $21: 00$ & Яльчинское & 86 & сосна & 2 \\
\hline$\ldots$ & $\ldots$ & $\ldots$ & $\ldots$ & ... & $\ldots$ & $\ldots$ & ... \\
\hline 23.05 .2011 & $16: 10$ & $16: 10$ & $17: 30$ & Кленовогорское & 27 & осина & 0.001 \\
\hline 26.07 .2011 & $9: 30$ & $9: 30$ & $14: 00$ & Яльчинское & 32 & сосна & 0.01 \\
\hline 07.08 .2011 & $17: 30$ & $17: 30$ & 19:00 & Яльчинское & 59 & сосна & 0.01 \\
\hline 13.08 .2011 & $20: 00$ & $20: 15$ & 14.08 & Кленовогорское & 26 & сосна & 0.015 \\
\hline
\end{tabular}


Исходные данные для статистического моделирования. По данным Книги учета лесных пожаров дополнительно были определены следующие показатели для статистического моделирования (табл. 2):

1) время с начала регистрации (сутки). при этом для первой регистрация пожара 01.08.1982 время с начала регистрации время равно нулю;

2) годы текущего времени (лет);

3) время по пожароопасному сезону года (сутки);

4) промежуток между пожарами по времени обнаружения (сутки).

Промежуток времени между пожарами по времени их обнаружения рассчитывается так: из даты последующего пожара вычитается дата предыдущего пожара. С учетом високосного года учитывается промежуток времени после последнего пожара в данном году до первого пожара в следующем календарном году.

Выглядит это так: 16.08.1982 - 01.08.1982=15 суток. Время с начала регистрации рассчитывается за все годы вместе. причем как кумулята: $0+15=15 ; 15+11=26 ; 26$ + $3=29 ; 29+0=29 ; 29+3=32$ и т.д..

Годы текущего времени получаются. начиная с нуля для первого года.

Время по сезону года (сутки) рассчитывается аналогично как время с начала регистрации только отдельно по годам.

Таблица 2. Данные по динамике лесных пожаров по временным параметрам в ФГУ «Национальный парк «Марий Чодра» за 1982-2011 гг.

\begin{tabular}{|c|c|c|c|c|c|c|c|c|c|}
\hline \multirow[b]{2}{*}{$\begin{array}{c}\text { № } \\
\Pi / \Pi\end{array}$} & \multirow[b]{2}{*}{\begin{tabular}{|c|} 
Дата \\
регистрации \\
лесного \\
пожара
\end{tabular}} & \multirow{2}{*}{$\begin{array}{c}\text { Проме- } \\
\text { жуток } \\
\text { времени } \\
\text { между } \\
\text { пожа- } \\
\text { рами. } \\
\text { сутки }\end{array}$} & \multirow{2}{*}{$\begin{array}{c}\text { Время } \\
\text { с начала } \\
\text { регистра- } \\
\text { ции. } \\
\text { сутки }\end{array}$} & \multirow[b]{2}{*}{$\begin{array}{c}\text { Годы } \\
\text { текущего } \\
\text { времени. } \\
\text { лет }\end{array}$} & \multirow{2}{*}{\begin{tabular}{|c|} 
Время \\
по \\
пожа- \\
роопас \\
ному \\
\\
сезону. \\
сутки
\end{tabular}} & \multicolumn{3}{|c|}{$\begin{array}{c}\text { Временные параметры } \\
\text { лесного пожара. ч }\end{array}$} & \multirow{2}{*}{$\begin{array}{c}\text { Площадь } \\
\text { распро- } \\
\text { странения } \\
\text { лесного } \\
\text { пожара. } \\
\text { га }\end{array}$} \\
\hline & & & & & & $\begin{array}{c}\text { Время } \\
\text { обнару- } \\
\text { жения }\end{array}$ & $\begin{array}{l}\text { Начало } \\
\text { тушения }\end{array}$ & $\begin{array}{c}\text { Окон- } \\
\text { чание } \\
\text { тушения }\end{array}$ & \\
\hline 1 & 01.08 .1982 & 0 & 0 & 0 & 0 & 19.58 & 20.08 & 5.33 & 0.6 \\
\hline 2 & 16.08 .1982 & 15 & 15 & 0 & 15 & 16.83 & - & 8.50 & - \\
\hline 3 & 27.08 .1982 & 11 & 26 & 0 & 26 & 14.92 & 18.00 & 19.00 & 0.03 \\
\hline 4 & 30.08 .1982 & 3 & 29 & 0 & 29 & 15.83 & 16.00 & 14.00 & 0.02 \\
\hline 5 & 30.08 .1982 & 0 & 29 & 0 & 29 & 18.00 & 18.67 & 22.00 & 0.02 \\
\hline 6 & 02.09 .1982 & 3 & 32 & 0 & 32 & 16.83 & 17.00 & 20.00 & 0.02 \\
\hline 7 & 15.05 .1 & 256 & 287 & 1 & 0 & 16.00 & 16.50 & 21.00 & 2 \\
\hline 8 & 30.05 .1983 & 15 & 302 & 1 & 15 & 14.67 & 15.17 & 19.00 & 0.01 \\
\hline$\ldots$ & ... & $\cdots$ & $\cdots$ & $\ldots$ & $\ldots$ & $\ldots$ & $\ldots$ & $\ldots$ & $\ldots$ \\
\hline 257 & 23.05 .2011 & 253 & 10584 & 29 & 255 & 16.17 & 16.17 & 17.5 & 0.001 \\
\hline 258 & 26.07 .2011 & 64 & 10648 & 29 & 63 & 9.5 & 9.5 & 14 & 0.01 \\
\hline 259 & 07.08.2011 & 12 & 10660 & 29 & 11 & 17.5 & 17.5 & 19 & 0.01 \\
\hline 260 & 13.08.2011 & 6 & 10666 & 29 & 6 & 20 & 20.25 & - & 0.015 \\
\hline
\end{tabular}


Остальные четыре параметра лесного пожара. приведенные в таблице 2. получаются из данных таблицы 1 при переводе минут в десятичные доли часа.

Всего в книге учета за период 1982-2011 гг. оказалось 260 лесных пожаров.

Для метода были отобраны шкалы времени (табл. 3): $t$ - время с начала регистрации. сутки; $t_{2}$ - годы текущего времени. лет. Время обнаружения и окончания тушения сами по себе не имеют факторного значения. но вычитанием дают продолжительность или период лесного пожара $T$. Основным физическим параметром для измерения потушенного лесного пожара является фактор - площадь лесного пожара (территория. пройденная пожаром) $S$.

Взаимные отношения между параметрами $T$ и $S$ дают еще два показателя:

$s_{T}=S / T$ - средняя скорость каждого лесного пожара, $\mathrm{m}^{2} / \mathrm{c}$;

$\tau_{S}=T / S$ - удельное время каждого лесного пожара. с/м².

Однако по шести строкам оказались прочерки в массиве данных по площади пожара. поэтому остались 254 строки в таблице 3 за 30 лет.

Таблица 3. Данные по динамике выделенных параметров лесных пожаров в ФГУ «Национальный парк «Марий Чодра» за 1982-2009 гг.

\begin{tabular}{|c|c|c|c|c|c|c|c|c|c|}
\hline $\begin{array}{c}\text { № } \\
\Pi / \Pi\end{array}$ & $\begin{array}{c}\text { Дата } \\
\text { регистрации } \\
\text { лесного } \\
\text { пожара }\end{array}$ & $\begin{array}{c}\text { Время } \\
\text { с начала } \\
\text { регистра } \\
\text { ции } \\
t \text {. сутки }\end{array}$ & $\begin{array}{c}\text { Годы } \\
\text { текущего } \\
\text { времени } \\
t_{2} . \text { лет }\end{array}$ & $\begin{array}{c}\text { Время } \\
\text { обнару- } \\
\text { жения }\end{array}$ & $\begin{array}{c}\text { Окон- } \\
\text { чание } \\
\text { тушения }\end{array}$ & $\begin{array}{c}\text { Продолжи- } \\
\text { тельность } \\
\text { пожара } \\
T .4\end{array}$ & $\begin{array}{c}\text { Площадь } \\
\text { лесного } \\
\text { пожара } \\
S . \text { га }\end{array}$ & $\begin{array}{c}\text { Средняя } \\
\text { скорость } \\
\text { пожара } \\
s_{T} \cdot \mathrm{M}^{2} / \mathrm{c}\end{array}$ & $\begin{array}{c}\text { Удельное } \\
\text { время } \\
\text { тушения } \\
\tau_{s} \cdot \mathrm{c}^{2}{ }^{2}\end{array}$ \\
\hline 1 & 01.08 .1982 & 0 & 0 & 19.58 & 5.33 & 9.75 & 0.6 & 0.1709 & 5.85 \\
\hline 2 & 27.08 .1982 & 26 & 0 & 14.92 & 19.00 & 4.08 & 0.03 & 0.0204 & 48.96 \\
\hline 3 & 30.08 .1982 & 29 & 0 & 14.00 & 15.83 & 1.83 & 0.02 & 0.0304 & 32.94 \\
\hline 4 & 30.08 .1982 & 29 & 0 & 18.00 & 22.00 & 4 & 0.02 & 0.0139 & 72.00 \\
\hline \multirow[t]{2}{*}{5} & 02.09 .1982 & 32 & 0 & 16.83 & 20.00 & 3.17 & 0.02 & 0.0175 & 57.06 \\
\hline & $\ldots$ & $\ldots$ & $\ldots$ & ... & $\ldots$ & $\ldots$ & $\ldots$ & $\ldots$ & $\ldots$ \\
\hline 250 & 31.07 .2010 & 10288 & 28 & 12.25 & 13.083 & 0.833 & \begin{tabular}{|l|}
0.0075 \\
\end{tabular} & 0.0250 & 39.98 \\
\hline 251 & 12.09 .2010 & 10331 & 28 & 18.083 & 19.5 & 1.417 & 0.005 & 0.0098 & 102.02 \\
\hline 252 & 23.05 .2011 & 10584 & 29 & 16.17 & 17.5 & 1.33 & 0.001 & 0.0021 & 478.80 \\
\hline 253 & 26.07 .2011 & 10648 & 29 & 9.5 & 14 & 4.5 & 0.01 & 0.0062 & 162.00 \\
\hline 254 & 07.08.2011 & 10660 & 29 & 17.5 & 19 & 1.5 & 0.01 & 0.0185 & 54.00 \\
\hline
\end{tabular}

Влияние времени в годах. Вначале был проверен массив исходных данных из 254 пар чисел и выяснены четыре резко отклоняющиеся точки: 16 8; 2 3; 33 и 143.

Тогда можно оценить качество функционирования системы пожаротушения НП «Марий Чодра» как долевое отношение $100 \times(254$ - 4) / $254=98.43 \%$. А оперативность работы этой же системы будет равна $T_{\max }=23$ ч. 
Таким образом, на особо охраняемых территориях действительно оперативно выполняется обнаружение и тушение лесных пожаров. Поэтому площади в 3 и 8 гектаров оказались чрезмерными для всей статистические выборки за 30 лет. Такие выбросы отдельно для каждого случая моделируются импульсными функциями гауссова закона нормального распределения [3-5].

На рисунке 1 дан график изменения площади лесного пожара по 250 точкам в зависимости от текущего времени в годах.

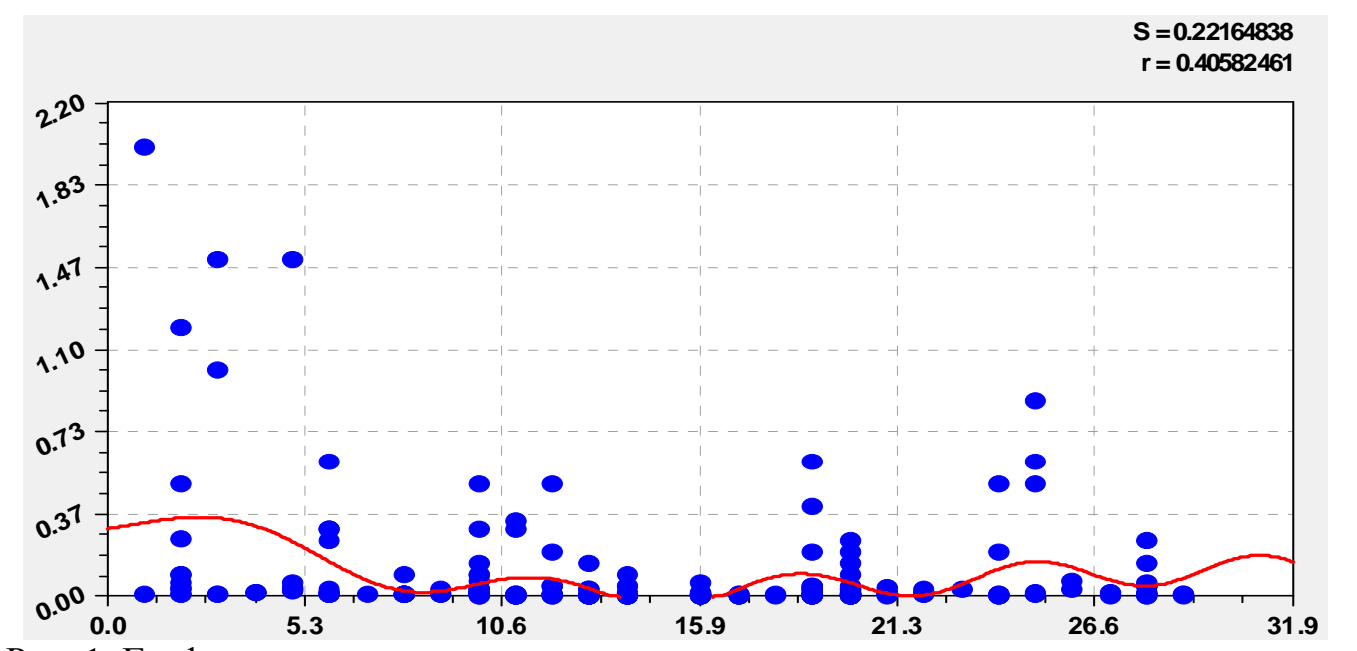

Рис. 1. График изменения площади лесного пожара от времени измерения в годах (цикл обращения Земли вокруг Солнца) с начала регистрации лесных пожаров

Этот график относится к слабому уровню тесноты факторной связи (коэффициент корреляции 0.4058) по формуле

$$
\begin{gathered}
S=S_{1}+S_{2}+S_{3} . \\
S_{1}=0.35491 \exp \left(-0.00057891 t_{2}^{1.95676}\right) . \\
S_{2}=-0.0087112 t_{2}^{2.94653} \exp \left(-0.56895 t_{2}^{0.75848}\right) \cdot S_{3}=A \exp \left(\pi t_{2} / p+0.66297\right) . \\
A=-0.064812 \exp \left(-0.0011942 t_{2}\right) \cdot p=7.04209-1.78064 t_{2}^{0.19859} .
\end{gathered}
$$

Формула (1) содержит три составляющие. из которых первые две являются членами тренда (тенденции). а третий член характеризуется как асимметричный вейвлет.

Для статистического моделирования была предложена методология идентификации [1. 2]. Она кратко показана в таблицах 4 и 5.

Идентификация структурная. Декарт предполагал существование одногоединственного алгебраического уравнения. пригодного как вариант решения для любых типов интегральных уравнений. Гильберт мечтал об инвариантах. из которых как из кирпичиков будет собираться это универсальное уравнение. 
Наши универсальные инварианты даны в таблице 4.

Таблица 4. Математические конструкты (исходные инварианты) для моделирования

\begin{tabular}{|c|c|}
\hline $\begin{array}{l}\text { и } \\
\text { оцесса }\end{array}$ & $\begin{array}{l}\text { гй } \\
\text { роцесса }\end{array}$ \\
\hline $\begin{array}{l}y=a x-\text { закон линейного роста или спада (при } \\
\text { отрицательном знаке перед правой стороной } \\
\text { формулы линейного изменения) }\end{array}$ & $\begin{array}{l}y=a-\text { закон не влияния принятой объясняю- } \\
\text { щей переменной на показатель. который имеет } \\
\text { собственную предысторию значений }\end{array}$ \\
\hline $\begin{array}{l}y=a x^{b}-\text { закон показательного роста (закон } \\
\text { показательной гибели } y=a x^{-b} \text { не является } \\
\text { устойчивым. из-за бесконечности показателя } \\
\text { при нулевом значении объясняющей перемен- } \\
\text { ной) }\end{array}$ & $\begin{array}{l}y=a \exp ( \pm c x) \text { - закон Лапласа в математике } \\
\text { (Ципфа в биологии. Парето в экономике. Ман- } \\
\text { дельброта в физике) экспоненциального роста } \\
\text { или гибели. относительно которого Лаплас } \\
\text { создал методологию операторного исчисления }\end{array}$ \\
\hline $\begin{array}{l}y=a x^{b} \exp (-c x)-\text { биотехнический закон в уп- } \\
\text { рощенной форме (П.М. Мазуркин). когда по- } \\
\text { казательный рост постепенно получает экспо- } \\
\text { ненциальное торможение }\end{array}$ & $\begin{array}{l}y=a \exp \left( \pm c x^{d}\right)-\text { закон экспоненциального } \\
\text { роста или гибели в полной форме (конструк- } \\
\text { ции). который имеет интенсивность. не рав- } \\
\text { ную единице (П.М. Мазуркин) }\end{array}$ \\
\hline
\end{tabular}

Они сгруппированы по принципу «от простого к сложному». По сути. фрагменты и сам биотехнический закон являются «кирпичиками Гильберта» для построения. в ходе процесса структурно-параметрической идентификации. аддитивной конструкции искомой статистической детерминированной или волновой модели.

Инварианты колебательных возмущений в виде асимметричных вейвлет-сигналов включают в себя конструкты из таблицы 4 как амплитуда (половина) и полупериод.

В таблице 4 показаны все наиболее встречающиеся инварианты (фрагменты). У них впереди могут быть расположены оперативные константы «+» или «-». Шесть устойчивых законов распределения являются частными случаями биотехнического закона. показанного внизу таблицы 4. В названии закона слово «биотехнический» означает. что мы придерживаемся идей В.И. Вернадского о космической функции жизни.

Если известны эвристическая предыстория формирования числового поля (табличной модели). то вполне возможна смысловая расшифровка каждого вейвлет-сигнала. у которого вейвлет (волновая функция) в своей конструкции содержит те или иные математические инварианты из таблицы 4.

Устойчивые законы и закономерности на их основе делают выбор уравнения для последующей идентификации на статистических данных (числовых полях) вполне осмысленным. и поэтому вероятностное моделирование остается только при случайном поиске программной средой типа CurveExpert значений параметров у искомой модели. Поэтому из теории идентификации первый этап (выбор случайной структуры уравнения) исключается и остается только второй этап - случайная идентификация значений 
параметров искомой модели.

Идентификация структуры модели проводится обработкой исходных данных так:

- вначале выявить детерминированные нелинейные закономерности;

- затем дополнять эти трендовые закономерности колебательными возмущениями.

Идентификация параметрическая. Она выполнялась в программной среде CurveExpert-1.38 или CurveExpert-1.40 (Программная среда CurveExpert. - URL : http://www.curveexpert.net/) и информационной технологией идентификации пользуются студенты (будущие бакалавры и магистры). а также аспиранты и докторанты.

Выбор структуры искомой модели. которая является алгебраическим решением по Декарту для неизвестной первообразной по волновым уравнениям. имеющим переменные амплитуду и полупериод (половины частоты как обратная величина полупериода) колебательного возмущения объекта исследования. выполняется из устойчивых законов (инвариантов). приведенных в таблице 4.

Процесс параметрической идентификации автоматически прекращается по условию достижения параметров модели некоторого минимального приращения и останавливается пользователем при достижении конструируемой моделью погрешности измерений для заданного числового поля. В нашем случае поиск прекращается из-за появления шума. который возникает из-за шкалы времени с большими интервалами (год) по формуле (1). или же из-за невозможности дальнейшего продолжения процесса идентификации устойчивых законов в виде вейлвет-сигналов при шкале измерения в сутках.

Уровни адекватности выявляемых закономерностей. В таблице 5 приведены интервалы изменения коэффициента корреляции как меры адекватности модели (или меры тесноты связи между двумя факторами).

Таблица 5. Уровни тесноты факторных связей

\begin{tabular}{|c|c|c|c|}
\hline \multirow{2}{*}{$\begin{array}{c}\text { Интервал } \\
\text { коэффициента } \\
\text { корреляции } \\
\end{array}$} & \multicolumn{3}{|c|}{ Характер тесноты связи между факторами } \\
\hline & $\begin{array}{l}\text { существующая } \\
\text { классификация }\end{array}$ & $\begin{array}{l}\text { шкала для техниче- } \\
\text { ских измерений }\end{array}$ & $\begin{array}{c}\text { шкала для прецизионных } \\
\text { измерений }\end{array}$ \\
\hline 1 & \multirow{5}{*}{ сильная связь } & однозначная & однозначная \\
\hline $0.99 \ldots 1.00$ & & \multirow{3}{*}{ сильнейшая } & почти однозначная \\
\hline $0.95 \ldots 0.99$ & & & сверхсильная \\
\hline $0.90 \ldots 0.95$ & & & сильнейшая \\
\hline $0.7 \ldots 0.9$ & & сильная & сильная \\
\hline $0.5 \ldots 0.7$ & \multirow{2}{*}{ слабая связь } & средняя & средняя \\
\hline $0.3 \ldots 0.5$ & & слабоватая & слабоватая \\
\hline $0.1 \ldots 0.3$ & \multirow{3}{*}{ нет связи } & слабая & слабая \\
\hline $0.0 \ldots 0.1$ & & слабейшая & слабейшая \\
\hline 0 & & нет связи & нет связи \\
\hline
\end{tabular}

Существующая шкала квантификации тесноты связи между принятыми факторами 
(нет связи. слабая и сильная связь) является очень грубой.

Нами было доказано. что именно анализ слабых связей. отбрасываемых при линейном моделировании и применении среднеарифметической факторной связи по закону Гаусса (нормального распределения). дает новые научные идеи и последующие научно-технические решения (получено более 95 патентов на изобретения по способам).

При анализе литературы по математической статистике было выявлено. что в аппроксимации сплошь и рядом применяется только линейная модель или же не имеющий физического смысла алгебраический полином. Это происходит из-за того. что линейная модель инвариантна к любому типу распределения. в том числе и явно негауссовой структуры. и даже к скедастическим данным измерений с переменной дисперсией.

Поэтому нами была предложена для технических экспериментов. в которых погрешность измерений не превышает 5\%. другая шкала (третий столбец таблицы 5). Однако выяснилось. что этой шкалы уровней адекватности также недостаточно.

Для многих природных (биологических) объектов и результатов прецизионных физических измерений пришлось ввести еще два интервала уровня адекватности по четвертому столбцу таблицы 5.

Влияние времени в сутках. Именно физический параметр - цикл обращения Земли вокруг своей оси. то есть сутки. стал основным влияющим параметром в процессе физико-математического анализа. Введение шкалы времени в сутках изменило поведение лесных пожаров как популяции за 30 лет на территории национального парка.

При этом первые три составляющие (рис. 2) оказались примерно с такой же адекватностью. как это было для формулы (1). при коэффициенте корреляции 0.4019. Но применение единицы измерения времени регистрации в сутках позволила дать большое множество волновых членов обобщенного уравнения.

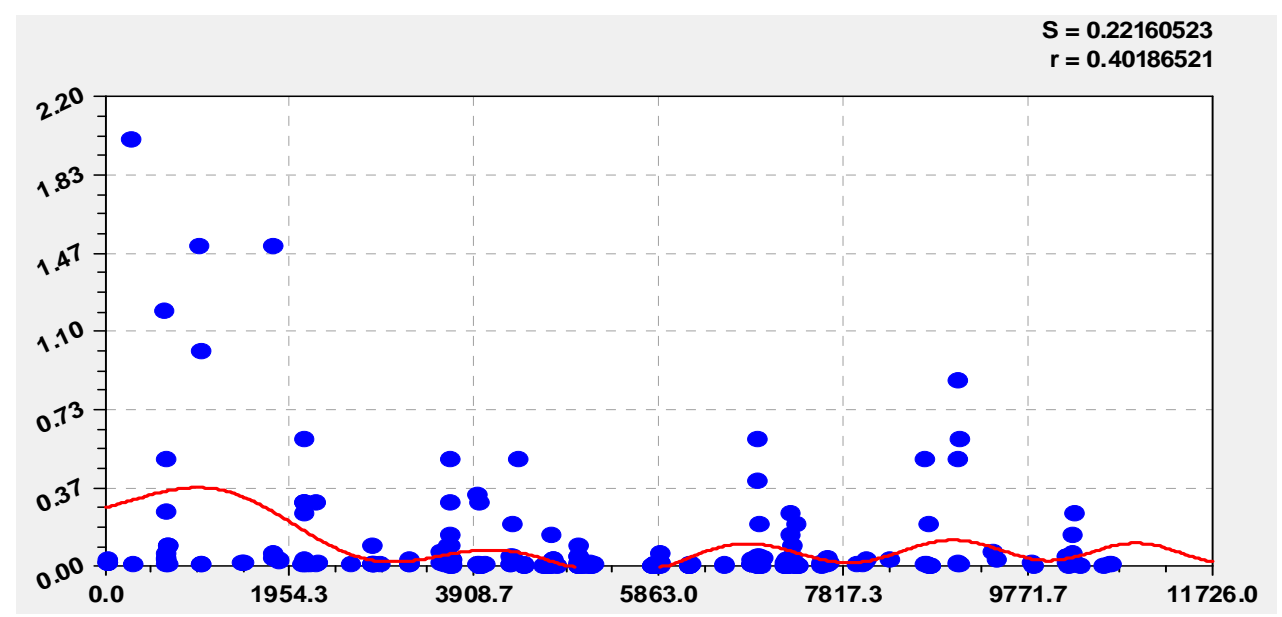

Рис. 2. График изменения площади лесного пожара от времени измерения в сутках 
Асимметричный вейвлет. Мы придерживаемся концепции Декарта о необходимости применении алгебраического уравнения общего вида напрямую как конечного математического решения неизвестных интегральных уравнений [1. 2].

Условиям существования удовлетворяет асимметричная вейвлет-функция вида

$$
y=\sum_{i=1}^{m} y_{i} \cdot y_{i}=a_{1 i} x^{a_{2 i}} \exp \left(-a_{3 i} x^{a_{4 i}}\right) \cos \left(\pi x /\left(a_{5 i}+a_{6 i} x^{a_{7 i}} \exp \left(-a_{8 i} x^{a_{9 i}}\right)-a_{10 i}\right) .\right.
$$

где $y$ - показатель (зависимый фактор). в нашем примере площадь лесного пожара. га. $i$ - номер составляющей модели (2). $m$ - количество членов в модели (2). причем косинус является связующим звеном между геометрией и алгеброй. $x$ - объясняющая переменная (влияющий фактор). в нашем случае время регистрации в сутках. $a_{1} \ldots a_{10}-$ параметры. принимающие числовые значения в ходе структурно-параметрической идентификации (2) по мере увеличения коэффициента корреляции.

В большинстве случаев для идентификации закономерностей достаточна усеченная конструкция (по вложенной в тригонометрическую функцию формуле частоты колебания) асимметричного вейвлета типа

$$
y=\sum_{i=1}^{m} y_{i} \cdot y_{i}=a_{1 i} x^{a_{2 i}} \exp \left(-a_{3 i} x^{a_{4 i}}\right) \cos \left(\pi x /\left(a_{5 i}+a_{6 i} x^{a_{7 i}}\right)-a_{8 i}\right) .
$$

Как правило. общая стохастическая волновая функция (3). в которой не волновые части (1) становятся частными случаями и показывают детерминированное на интервале времени измерений поведение объекта исследования. позволяет идентифицировать составной статистической моделью поведение многих астрономических и физических. биологических и экологических. социально-экономических и иных объектов.

Динамический ряд как череда сигналов. Физико-математический подход [1-12] предполагает понимание смысла динамического ряда как отражения какого-то составного реального процесса или же множества последовательно и параллельно происходящих природных и/или природно-антропогенных реальных процессов.

Впервые удалось получать модели многих типов рядов динамики на концепции аддитивного разложения любого динамического ряда на множество сигналов.

На рисунках 3-6 показаны графики полного (возможного по точности измерений) физико-математического анализа динамики лесных пожаров за 1982-2011 ги.. то есть за период в 30 лет. на территории предприятия «Национальный парк «Марий Чодра». 

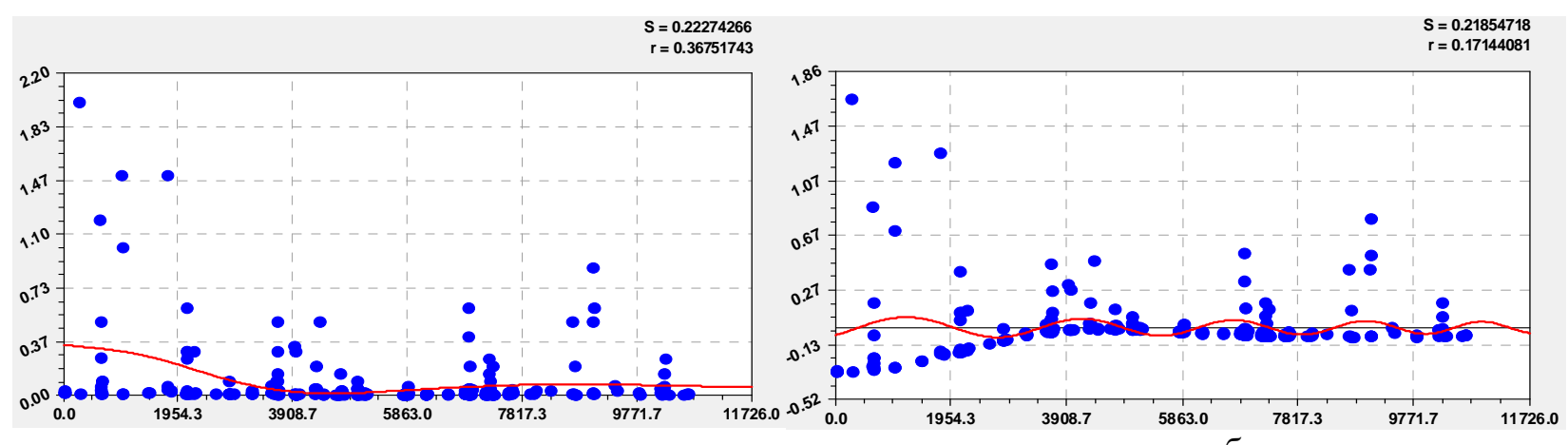
тренд
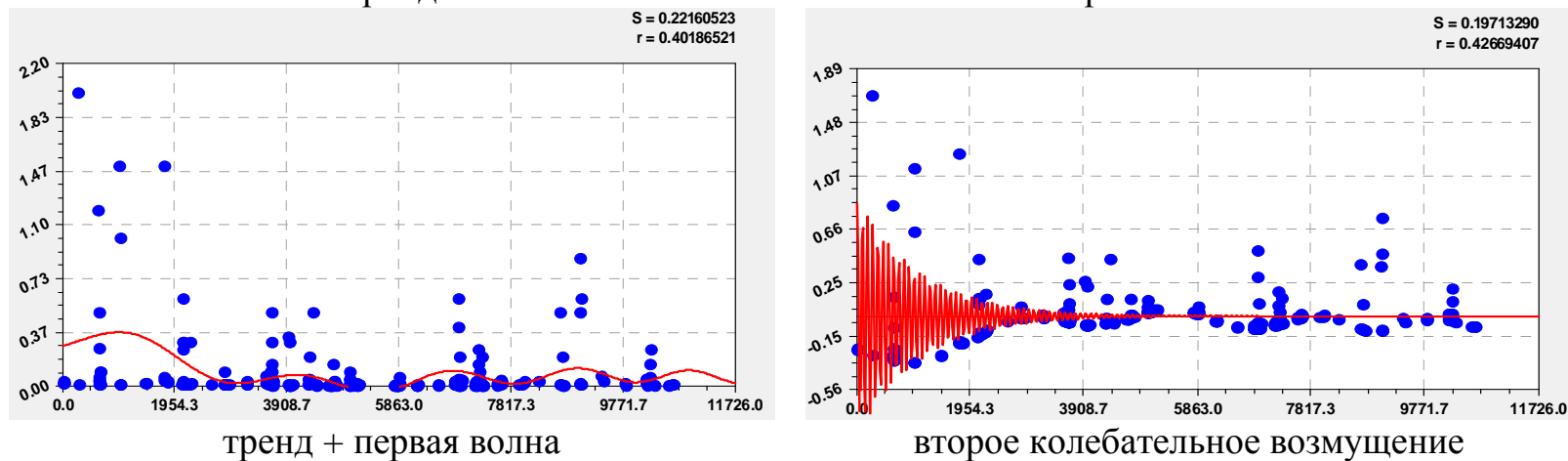
второе колебательное возмущение

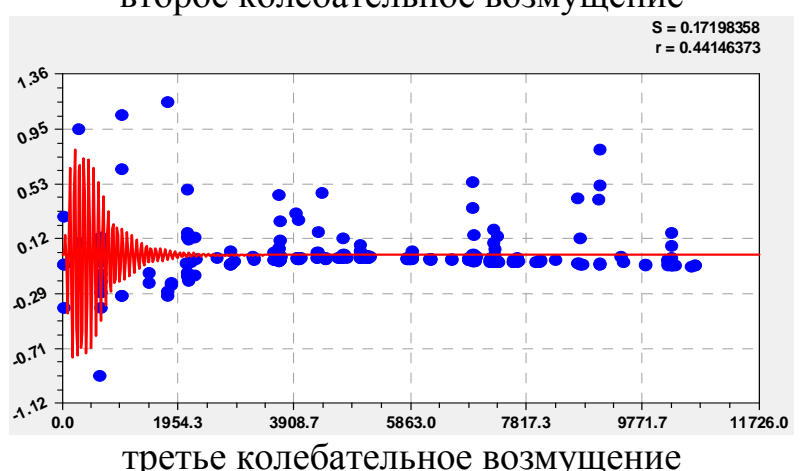

тренд + две волны
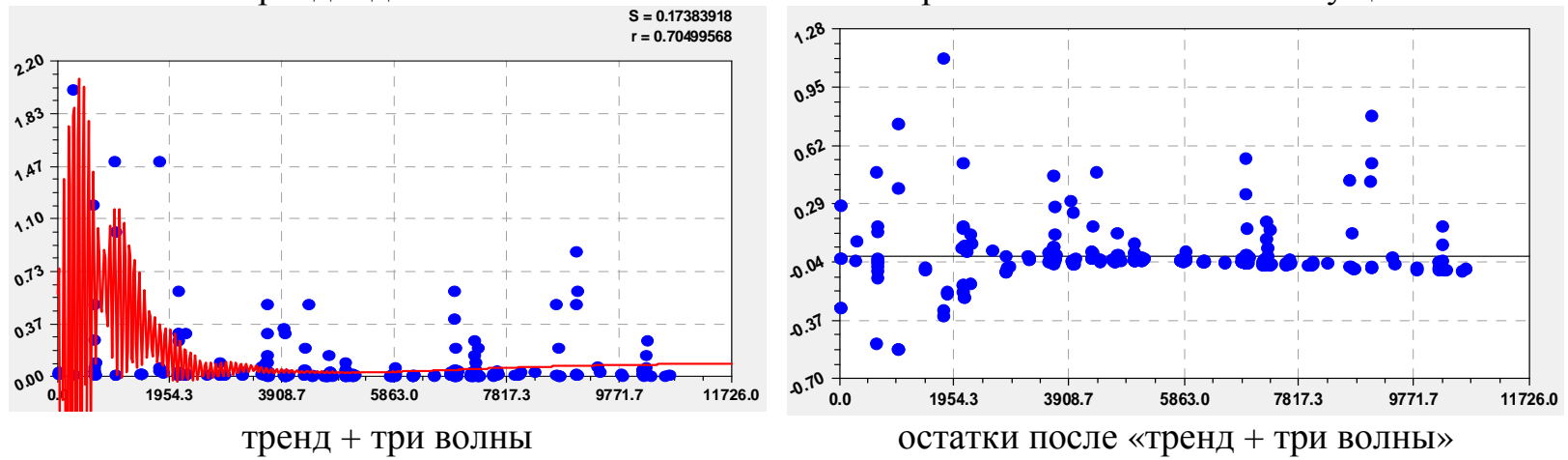

Рис. 3. Графики тенденции. трех волновых колебательных возмущений и их совместная динамика значений площади лесных пожаров за период 1982-2011 гг.. полученные по возможностям программной среды CurveExpert-1.40

(CurveExpert. URL : http://www.curveexpert.net/)

Сигнал - это материальный носитель информации. А информация нами понимается как мера взаимодействия. Сигнал может генерироваться. но его приём не обязателен. Так. например. ряд простых чисел известен несколько тысяч лет. но суть его как множества сигналов до сих пор не была раскрыта. 

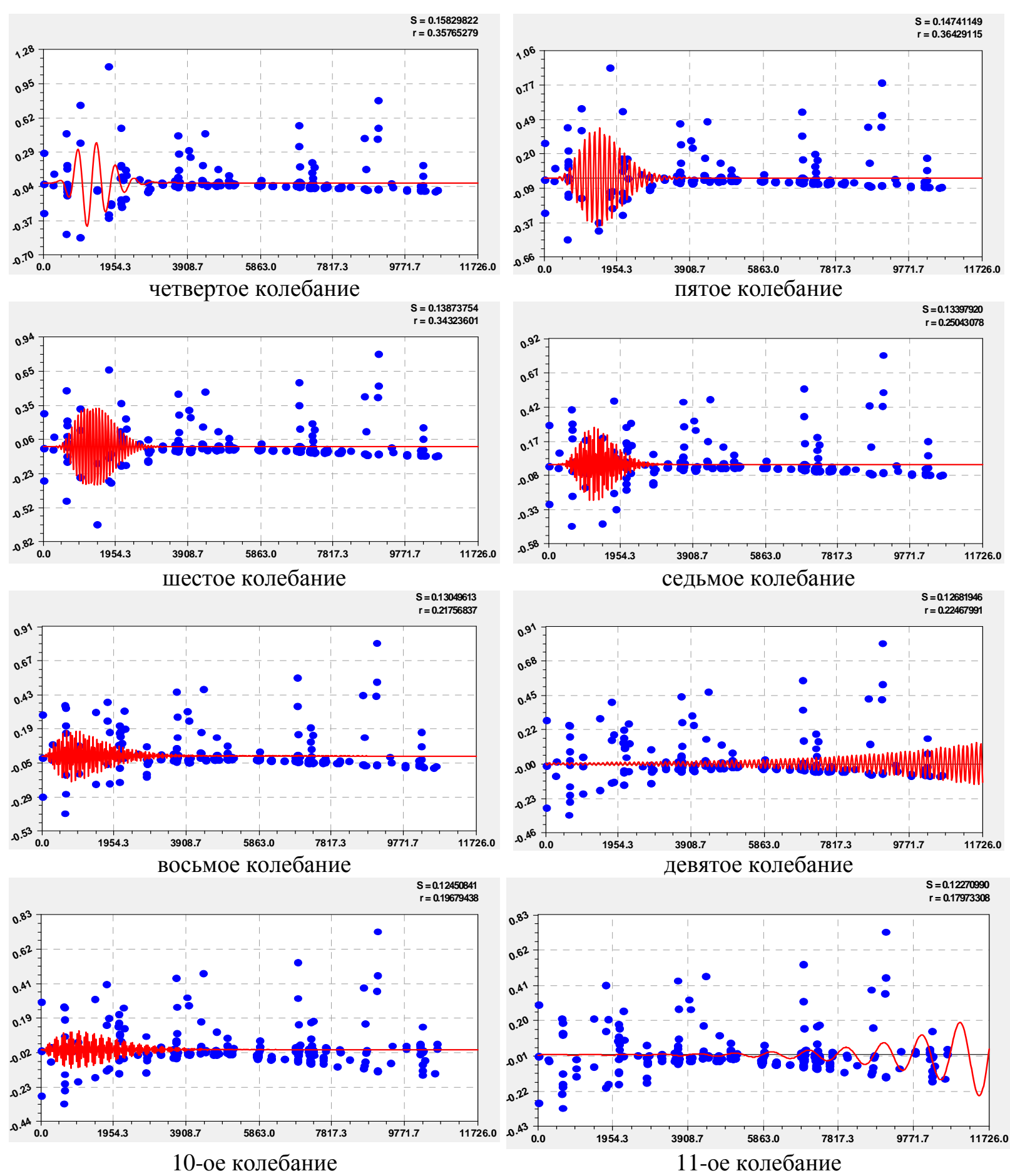

Рис. 4. Графики отдельных волновых уравнений (асимметричные вейвлет-сигналы)

по второй части составляющих общей статистической модели динамики площади лесных пожаров в зависимости от времени измерения в сутках за период 1982-2011 гг.

Сигналом может быть любой физический процесс или его часть.

Получается. что изменение множества неизвестных сигналов давно известно. например. через ряды гидрометеорологических и иных климатических [3] измерений во многих точках планеты. 

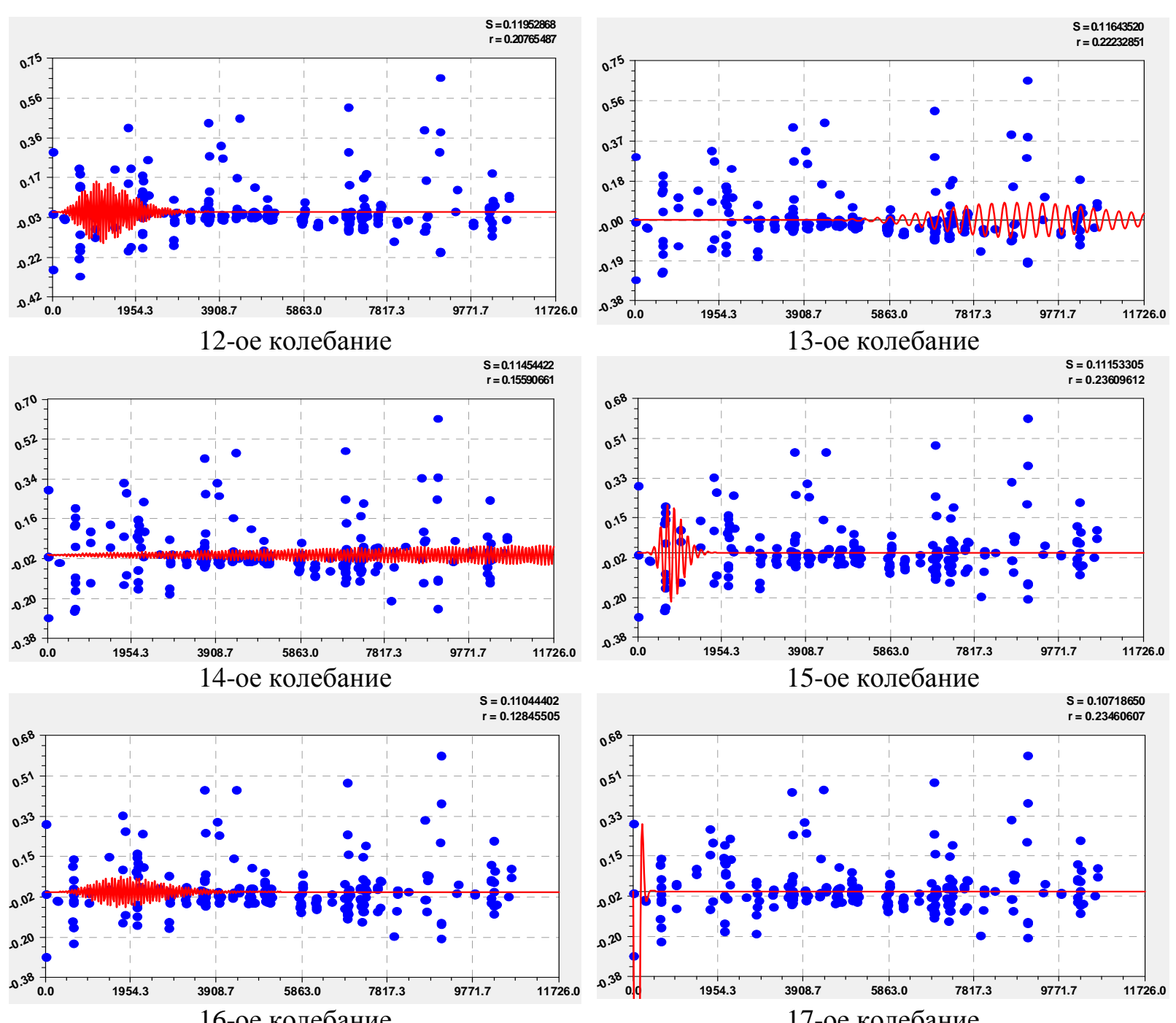

16-ое колебание

17-ое колебание

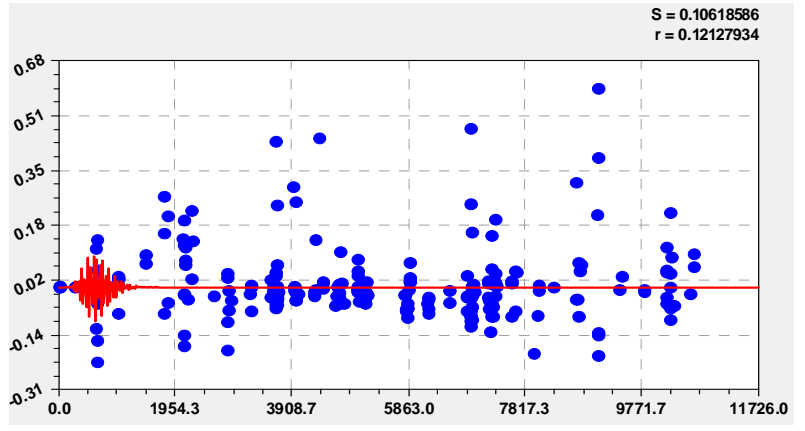

18-ое колебание

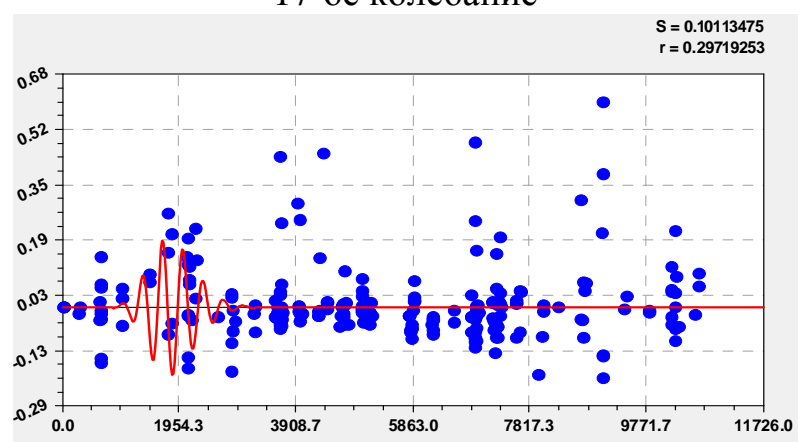

19-ое колебание

Рис. 5. Графики отдельных волновых уравнений (асимметричные вейвлет-сигналы) по второй части составляющих общей статистической модели динамики площади лесных пожаров в зависимости от времени измерения в сутках за период 1982-2011 гг. как продолжение физико-математического анализа массива статистических данных

Тогда любое уравнение типа (3) можем записать как асимметричный вейвлет

$$
y_{i}=A_{i} \cos \left(\pi x / p_{i}-a_{8 i}\right) \cdot A_{i}=a_{1 i} x^{a_{2 i}} \exp \left(-a_{3 i} x^{a_{4 i}}\right) \cdot p_{i}=a_{5 i}+a_{6 i} x^{a_{7 i}}
$$

где $A_{i}$ - амплитуда (половина) вейвлета (ось $y$ ). $p_{i}$ - полупериод колебания (ось $x$ ). По формуле (4) с двумя фундаментальными физическими постоянными $e$ 
(число Непера или число времени) и $\pi$ (число Архимеда или число пространства) образуется изнутри изучаемого явления и/или процесса квантованный вейвлет-сигнал. Понятие вейвлет-сигнала позволяет абстрагироваться от физического смысла самих рядов (в общем случае не только динамических) и рассматривать их аддитивное разложение.

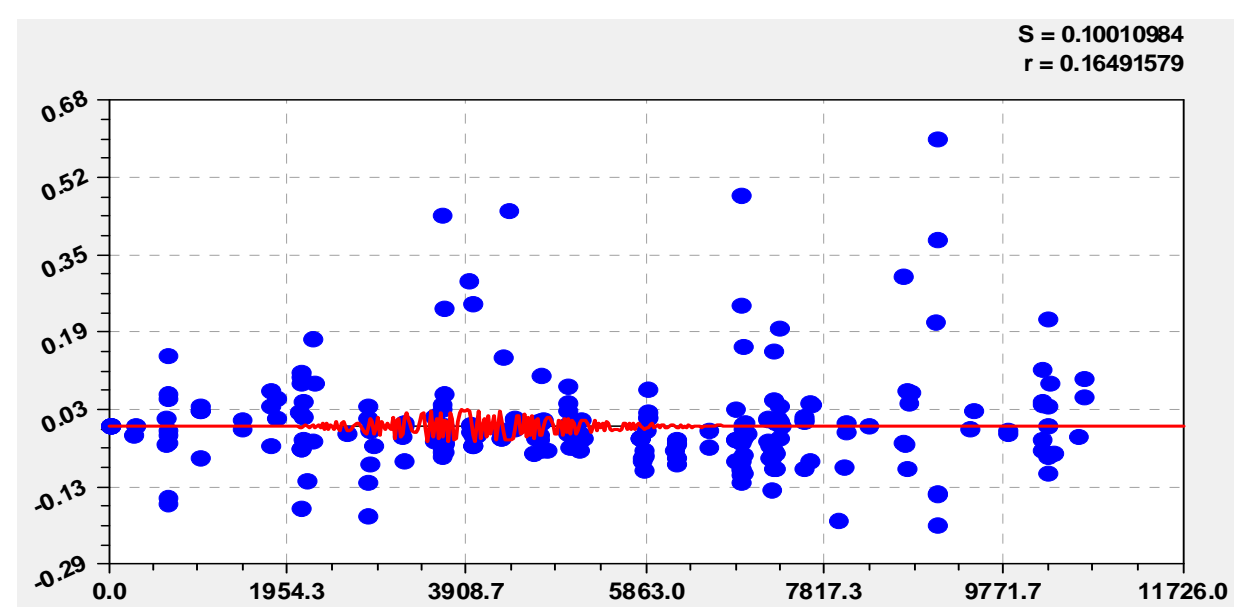

Рис. 6. Графики отдельных волновых уравнений по второй части составляющих общей статистической модели динамики площади лесных пожаров в зависимости от времени измерения в сутках за период 1982-2011 гг. как 20-е колебательное возмущение в виде асимметричного вейвлет-сигнала

Для краткой записи значений параметров уравнений всех 22 члена обобщенной функции (4) применена матричная форма (табл. 6).

Таблица 6. Параметры вейвлет-сигналов динамики площади лесных пожаров. га

\begin{tabular}{|c|c|c|c|c|c|c|c|c|c|}
\hline \multirow{2}{*}{$\begin{array}{c}\text { № } \\
i \\
\end{array}$} & \multicolumn{4}{|c|}{ Амплитуда колебания (4) } & \multicolumn{4}{|c|}{ Полупериод и сдвиг колебания (4) } & \multirow{2}{*}{$\begin{array}{l}\text { Коэфф. } \\
\text { коррел. }\end{array}$} \\
\hline & $a_{1 i}$ & $a_{2 i}$ & $a_{3 i}$ & $a_{4 i}$ & $a_{5 i}$ & $a_{6 i}$ & $a_{7 i}$ & $a_{8 i}$ & \\
\hline 1 & 0.099469 & 0 & $\mid$\begin{tabular}{|l|}
$1.10516 \mathrm{e}-6$ \\
\end{tabular} & 1.12425 & 0 & 0 & 0 & 0 & \multirow{5}{*}{0.7050} \\
\hline 2 & $-3.53087 e-20$ & 5.60399 & 0.0011208 & 1.00071 & 0 & 0 & 0 & 0 & \\
\hline 3 & -4.14493 & 0 & 0.0018387 & 1 & 3638.952 & -0.68395 & 1 & -1.39525 & \\
\hline 4 & 1.69642 & 0 & \begin{tabular}{|l|}
0.0012152 \\
\end{tabular} & 1 & 44.11963 & 0 & 0 & 0.78600 & \\
\hline 5 & $-5.41258 e-5$ & 3.76958 & 1.72078 & 0.33592 & 40.15229 & 0 & 0 & 0 & \\
\hline 6 & $-4.89109 e-20$ & 7.07555 & 0.0038303 & 1.05028 & 5.09452 & 0 & 0 & 1.80841 & 0.3577 \\
\hline 7 & $8.13875 \mathrm{e}-20$ & 6.88600 & 0.0048578 & 1 & 8.99494 & $5.66406 \mathrm{e}-11$ & 1 & 0.36339 & 0.3643 \\
\hline 8 & $1.11073 \mathrm{e}-22$ & 8.07420 & 0.0062925 & 1 & 5.95468 & $-1.48025 e-6$ & 1 & 4.07923 & 0.3432 \\
\hline 9 & $-8.31051 \mathrm{e}-20$ & 6.98146 & \begin{tabular}{|l|}
0.0057093 \\
\end{tabular} & 1 & 4.02093 & $6.47353 e-8$ & 1 & -0.021803 & 0.2504 \\
\hline 10 & $6.86038 \mathrm{e}-8$ & 2.93353 & 0.082222 & 0.60889 & 4.31117 & 0 & 0 & 0.90254 & 0.2176 \\
\hline 11 & -0.0061436 & 0 & -0.00027068 & 1 & 59.70359 & $-7.49475 \mathrm{e}-9$ & 1 & 1.83074 & 0.2247 \\
\hline 12 & $-1.75252 e-5$ & 1.50472 & \begin{tabular}{|l|}
0.0015981 \\
\end{tabular} & 1 & 3.01407 & $6.09900 \mathrm{e}-10$ & 1 & 3.21235 & 0.1968 \\
\hline 13 & 0.00088503 & 0 & -0.00048654 & 1.00082 & 454.9201 & 0.0019775 & 0.99997 & 3.09600 & 0.1797 \\
\hline 14 & $1.72624 \mathrm{e}-12$ & 4.18325 & 0.0037123 & 1 & 7.92140 & 0 & 0 & 1.95500 & 0.2077 \\
\hline 15 & $-8.09530 \mathrm{e}-83$ & 23.07698 & 0.0026183 & 1 & 1.50027 & 0 & 0 & -3.40294 & 0.2233 \\
\hline 16 & $7.58860 \mathrm{e}-5$ & 0.68221 & $6.02516 \mathrm{e}-7$ & 1 & 13.99570 & 0 & 0 & 0 & 0.1559 \\
\hline 17 & $3.33572 \mathrm{e}-26$ & 10.12949 & 0.012306 & 1.01046 & 3.31899 & 0 & 0 & -4.08812 & 0.2361 \\
\hline 18 & $6.35400 \mathrm{e}-16$ & 4.99166 & \begin{tabular}{|l|}
0.0027039 \\
\end{tabular} & 1.00677 & 1.00957 & 0 & 0 & -3.98463 & 0.1285 \\
\hline 19 & -0.060688 & 1.22372 & 0.023509 & 1 & 56.13935 & 0.075774 & 1 & -0.0027380 & 0.2346 \\
\hline 20 & $-9.60783 e-20 \mid$ & 7.74883 & 0.013405 & 1 & 1.40310 & 5.78986e-9 & 1 & -0.82540 & 0.1213 \\
\hline 21 & $-1.24998 \mathrm{e}-60$ & 20.98269 & 0.0099236 & 1.02126 & 1.49818 & 0 & 0 & 3.62390 & 0.2972 \\
\hline 22 & $|1.33889 \mathrm{e}-55|$ & 16.96104 & 0.0044297 & 1 & 1.49781 & $-9.24608 e-5 \mid$ & 1 & -4.72867 & 0.1649 \\
\hline
\end{tabular}


Остатки (рис. 7) после 22-го члена (20-ой волны колебательного возмущения) получили пару противоположно ориентированных значений при одной и той же абсциссе.

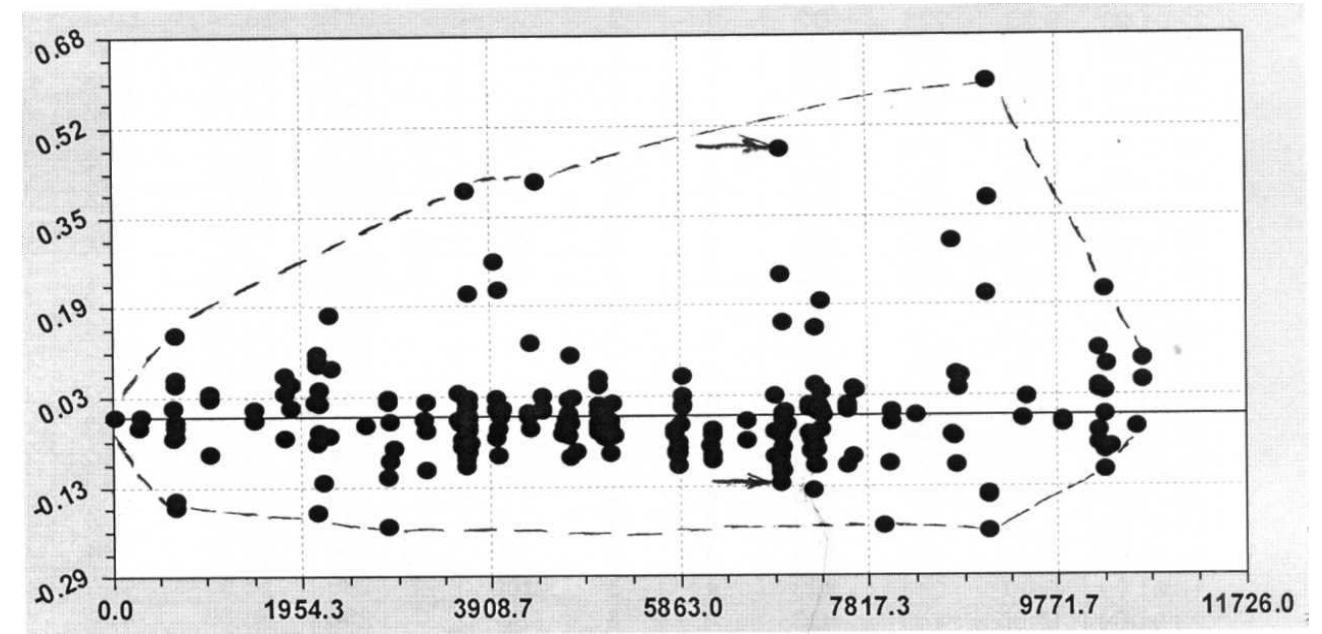

Рис. 7. Остатки после 20-го колебания в виде шума. который появляется из-за возникновения пары противоположно расположенных относительно оси абсцисс двух точек (показаны стрелками $t=6922$ суток $S=0.475544$ га и $t=6922$ суток $S=-0.119456$ га). а пунктирной линией показана динамика интервала разброса остатков.

Как видно из точечного распределения. разброс точек возрастает до этой пары (показаны стрелками). а затем по инерции разброс повышается. Но в конце периода измерений точность измерений повышается (разброс резко уменьшается). Поэтому нужно повышать точность регистрации лесных пожаров.

Заключение. Предлагаемый способ обладает простотой проведения. причем по выявленным закономерностям можно было бы выполнить ориентировочный инерционный прогноз на горизонт прогноза. равный основанию прогноза (промежутку времени от нуля до последнего измерения лесного пожара). а также рабочий инерционный прогноз на одну треть периода прошлых измерений лесных пожаров.

Применение предложенного способа расширяет возможности территориального экологического мониторинга. повышает функциональные возможности системы типа «Лесной Дозор». а также точности инерционного прогнозирования лесных пожаров. в её программной части - это специальное программное обеспечение. с помощью которого заказчик осуществляет мониторинг лесов в режиме реального времени с смоента регистрации первого на данной территории лесного пожара и определяет количество возгораний на одной и той же координате. В итоге появляется практическая возможность. с использованием многолетних данных о лесных пожарах на территории. экологического и технологического (пожаротушения) мониторинга для прогнозирования и уточнения распределения времени слежения аппаратной части системы на те или иные объекты по вы- 
явленным статистическим моделированием закономерностям. а также прогнозный расчет по ним значений параметров будущих лесных пожаров.

Положительный эффект достигается тем. что повышаются функциональные возможности системы типа «Лесной Дозор». а также точности инерционного прогнозирования лесных пожаров. в её программной части - это специальное программное обеспечение. с помощью которого заказчик осуществляет мониторинг лесов в режиме реального времени с смоента регистрации первого на данной территории лесного пожара и определяет количество возгораний на одной и той же координате.

Новизна технического решения заключается в том. что впервые выполнено преобразование пассивной статистической выборки из книги учета лесных пожаров в динамическую систему поведения локальной лесной точки на земной поверхности в зависимости от времени регистрации лесных пожаров. определяемых легко по датам и времени регистрации лесных пожаров. В итоге материальный объект в виде Земли (его суточные циклы) воздействует на популяцию лесных пожаров. то есть на материальный объект в виде постоянного лесного ландшафта на конкретной территории лесного предприятия. В связи с этим суточное время регистрации лесных пожаров становится влияющей физической переменной. позволяющей в дальнейшем увязать параметры различных природных явлений (освещенности. тепловой радиации. метеорологических показателей и пр.) с параметрами каждого единичного лесного пожара - периодом пожара. средней скоростью лесного пожара.

\section{Список литературы}

1. Мазуркин П.М. Идентификация статистических устойчивых закономерностей // Наука и мир: международный научный журнал. 2013. № 3(3). С.28-33.

2. Мазуркин П.М. Решение 23-ой проблемы Гильберта Междисциплинарные исследования в области математического моделирования и информатики. Матер. 3-й научнопрак. internet-конф. Ульяновск: SIMJET. 2014. C 269-277.

3. Мазуркин П.М.. Блинова К.С. Активность Солнца и годичная динамика лесных пожаров на особо охраняемой территории // Успехи современного естествознания. 2013. № 1. C.102-107.

4. Мазуркин П.М.. Блинова К.С.. Хазиев А.В. Асимметричные вейвлет-сигналы многолетней динамики численности лесных пожаров Республики Марий Эл // Вестник Казанского технол. ун-та. 2013. Т. 16. № 15. С.148-151.

5. Мазуркин П.М. Каткова Т.Е. Моделирование многолетней динамики изменения площади лесных пожаров // Вестник Воронежского института ГПС МЧС России. 2013. №1 (6). С.31-37.

6. Мазуркин П.М. Каткова Т.Е. Анализ многолетней динамики удельной площади лесных пожаров // Вестник Воронежского института ГПС МЧС России. 2013. №2 (7). C.37-43. 
7. Мазуркин П.М.. Каткова Т.Е. Вейвлет-анализ многолетней динамики локальной численности лесных пожаров // Современные проблемы науки и образования. - 2013. № 5; URL: http://www.science-education.ru/111-10164 (дата обращения: 26.09.2013).

8. Мазуркин П.М.. Скорикова Л.А. Динамика температуры горения древесных опилок при испытании сжиганием // Вестник КНИТУ. 2011. № 7. С.58-61.

9. Мазуркин П.М.. Филонов А.С. Математическое моделирование. Идентификация однофакторных статистических закономерностей: учеб. пос. Йошкар-Ола: МарГТУ. 2006. 292 c.

10. Пат. 2406079 Российская Федерация. МПК G 01 N 25 / 00. G 01 N 33 / 46 (2006.01). Способ испытания древесных материалов по температуре сгорания / Мазуркин П.М.. Кудрявиева Л.А. (РФ); заявитель и патентообладатель Марийск. гос. тех. ун-т. №2009133872/28; заявл. 09.09.2009; опубл. 10.12.2010.

11. Пат. 2449272 Российская Федерация. МПК G 01 N 33/46. А 01 G 23/00 (2006.01). Споосб испытания древесных материалов на горючесть / Мазуркин П.М. Кудрявцева Л.А.; заявитель и патентообладатель Марийский гос. тех. университет. №2009133878/15; заявл. 09.09.2009; опубл. 27.04.2012; Бюл. №12.

12. Пат. 2416793 Российская Федерация. МПК G 01 N 33 / 46. А 62 C 3 / 02 (2006.01). Способ испытания лесных горючих материалов на воспламеняемость / Мазуркин П.М.. Кудрявиева Л.А.. Егорова Е.А. (РФ); заявитель и патентообладатель МарГТУ. № 2009133875/12; заявл. 09.09.2009; опубл. 20.04.2011. 